\title{
Initiation of SHS processes
}

\author{
Vadim V. Barzykin \\ Institute of Structural Macrokinetics of the USSR Academy of Sciences, \\ 142432, Chernogolovka, Moscow region, USSR
}

\begin{abstract}
Results of experimental and theoretical studies on combustion initiation in SHS systems reported in literature and carried out by the author with his colleges for recent 20 years are reviewed. Different procedures of initiation of the process in SHS systems such as radiant flux ignition, laser induction, ignition by combustion wave, spark and hypergolic ignition, etc. are considered. Mathematical models used in different works for description of transition processes taking place in initiation of SHS are discussed. The most interesting theoretical and experimental data are presented. Qualitative and quantitative fitting of calculated data with experimental results is analyzed.
\end{abstract}

\section{INTRODUCTION}

Studies concerned with the initial stage (initiation) of SHS processes touch upon a number of problems appearing to be of interest from practical or theoretical point of view. A self-propagating high-temperature synthesis is a kind of combustion processes. The phenomenon of SHS was first discovered by A.G.Merzhanov, V.M.Shkiro, and I.P.Borovinskaya in 1967 (refs.1 and 2) on studying combustion of samples pressed from titanium and boron powders. At present, many (up to several hundreds) SHS reactions are already known. These are the reactions of direct synthesis from elements when both metals (titanium, tantalum, zirconium, hafnium, tungsten, molibdenum, etc.) and nonmetals (boron, carbon, silicon, nitrogen, hydrogen, etc.) are used as reactants as well as the reactions in multi-component systems consisting of both chemical elements and their compounds. Close to these systems by their physico-chemical nature are pyrotechnic and termite mixtures. A case of combustion of porous metal bodies in a gaseous oxidizing reagent (nitrogen, hydrogen) is also of great interest. A specific feature of most of these systems determined by the nature of interaction between components (deceleration of reaction by growing product layer) is their low inflammability. High energy needed for initiation of the process and high ignition temperature make a role of heat losses essential. There are many different techniques of initiation of SHS processes, viz., radiant flux ignition, ignition by means of laser radiation, by combustion wave, by heated gas, by heating coil, spàrk and hypergolic ignition, "chemical oven", electrothermal explosion, and thermal explosion with linear heating. These techniques differ both by the physical nature and by quantitative characteristics. Investigation of regularilities and mechanism of Ignition is important for working out reliable schemes and methods of initiation of SHS reactions as well as for providing fire and explosion safety of industrial procedure of manufacture of various substances and materials by means of SHS method. This review begins with description of experimental facilities used for realization of different techniques of SHS initiation. Then some mathematical models suggested by different authors for calculation of temperature and concentration fields as well as of characteristics of process will be discussed. And, at last, the most interesting experimental and theoretical data and some recommendations for selecting optimum conditions of ignition are given.

\section{EXPERIMENTAL METHODS OF STUDY AND TECHNIQUES OF INITIATION OF SHS PROCESS}

\section{Combustion wave ignition}

A typical preliminary procedure for carrying out a self-propagating high-temperature synthesis is compaction of original mixture to pellets of required density. A very popular way of initiation with such pellets is the use of igniter and transition mixtures. This manner of initiation of a SHS process was first proposed by the SHS discoverers themselves (ref.1). An igniter mixture was initiated by tungsten or nickel-chromium alloy coil and it was composed of the following components: $\mathrm{CaSi}_{2}, \mathrm{Fe}_{2} \mathrm{O}_{3}, \mathrm{Mg}, \mathrm{Al}_{2} \mathrm{O}_{3}, \mathrm{SiO}_{2}, \mathrm{Ti}$ and $\mathrm{B}$. The 
1 spring clip,

2 igniter,

$3 \operatorname{coil}$,

4 sample ignited,

5 housing,

6 nozzle body,

7 net,

8 silicagel,

9 glass cap.

Fig.1. Experimental scheme for investigat ion of the combust $i$ on wave ignition.

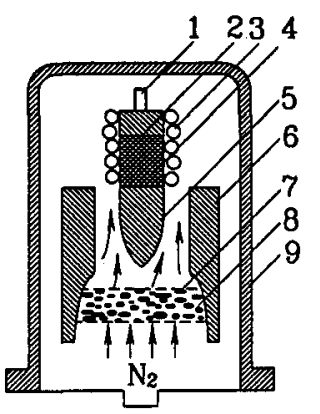

or

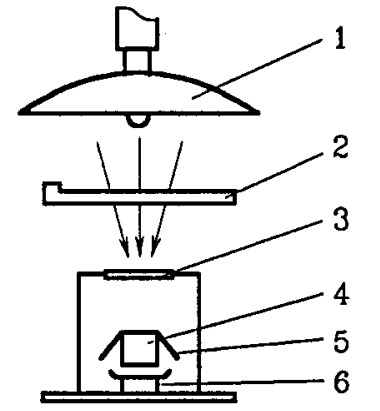

1 ref lector,

2 shutter ( $t$ ime of operat $i$ on $0.01 \mathrm{~s}$ ).

3 quartz window,

4 sample,

5 thermocouple,

6 sample holder.

Fig.2. Installation diagram for invest igation of the radiant flux ignition.

initiation in one of the variations was carried out with the use of igniter pressed from five different mixtures. A detailed study of ignition by combustion wave was undertaken by A.G.Strunina and by the author of this review and coworkers (refs.3-5). A transition process between cylindrical igniter tablets and initiated system was experimentally investigated. Using experimental scheme is shown in Fig.1.

Samples were placed on a support and fixed with a spring holder. Preliminary warming up or cooling of the samples was envisaged. The coefficient of heat transfer to the surroundings changed because of a change in gas flow rate. A rate of combustion front propagation was measured with a photoregister. In experiments on termite systems, different ignition modes were observed and characteristics of the process (delay time, energy and temperature of ignition) were determined.

\section{Radiant flux ignition}

This type of ignition provides a possibility fixing the conditions of occurrence of process. Since energy supply is performed in a contactless way, composition of the surroundings and intensity of the source can be varied independently. This is especially important for ignition of metal-gaseous oxidizer systems. An advantage of this ignition technique consists also in the fact that the source does not contaminate an ignited systems at all. V.P.Stovbun et.al. (refs.6 and 7) designed a facility providing a heat flux density of $6 \cdot 10^{6} \mathrm{~W} \cdot \mathrm{m}^{-2}$. An installation diagram is shown in Fig.2. A xenon lamp with a continuous emission spectrum ranging from 2000 to $18000 \AA$ was used as a radiation source. Heat flux density distribution not exceeding 5\% was provided in a circle of focal spot of $10 \mathrm{~mm}$ in diameter. A pulse duration was maintained as precise as $0.01 \mathrm{~s}$, with a minimum pulse duration of $0.1 \mathrm{~s}$. Samples for these experiments were prepared in a form of cylinder of 5 to $15 \mathrm{~mm}$ in diameter and of 3 to $12 \mathrm{~mm}$ in length (depending on heat flux density) from powders pressed up to a prescribed density so that the effect of heat losses through the side surface of sample and through a surface opposite to the irradiated area could be neglected. To reduce heat losses, the side surface was thermally insulated with a screen. A time dependence of temperature of sample surface was registered with a tungsten-rhenium thermocouple (40-50 $\mu \mathrm{m}$ thick) attached to or embedded in the sample surface. An ignition delay time was determined out of an oscillogramm for break-down of temperature curve with the accuracy not less than $27 . \mathrm{Ti}+\mathrm{C}, \mathrm{Zr}+\mathrm{C}, \mathrm{Ta}+$ $\mathrm{B}, \mathrm{Nb}+\mathrm{B}, \mathrm{Ti}+1 / 2 \mathrm{~N}_{2}, \mathrm{Nb}+1 / 2 \mathrm{~N}_{2}$, and $\mathrm{Zr}+1 / 2 \mathrm{~N}_{2}$ systems were studied. The ignition characteristics depending on heat flux density, on parameters of a system under study, and on pressure of environment were determined.

\section{Laser induced ignition}

Laser induced initiation of SHS systems was studied by many researchers (refs.8-11). Laser radiation was used for ignition of titanium powder in oxygen (ref.12). Different types of laser were utilized, viz. neodymium-doped glass laser with a pulse duration of $0.6 \cdot 10^{-3}$ to $5.2 \cdot 10^{-3} \mathrm{~s}$ (refs.8-10), ruby laser with a pulse duration of $0.5 \cdot 10^{-3} \mathrm{~s}$ (ref.12), and caesium bromide laser with a pulse duration of 1 to $52 \mathrm{~s}$ (ref.11). A specific feature of application of laser radiation is a possibility of obtaining very high heat flux densities (up to $10^{11} \mathrm{Wm}^{-2}$ ) which makes melting and vaporization of components to play an essential part during the ignition. A variety of SHS systems such as $\mathrm{Ti}+\mathrm{B}, \mathrm{Ti}+2 \mathrm{~B}, \mathrm{Ti}+\mathrm{C}, \mathrm{Ti}+2 \mathrm{Si}$, $\mathrm{Zr}+\mathrm{C}, \mathrm{Zr}+2 \mathrm{Si}, \mathrm{Mo}+2 \mathrm{Si}, \mathrm{Al}+\mathrm{Ni}$ and $2 \mathrm{Al}+\mathrm{Fe}_{2} \mathrm{O}_{3}, \mathrm{~B}+\mathrm{Ba}_{2} \mathrm{CrO}_{4}$, and $2 \mathrm{Al}+3 \mathrm{CuO}$ termite systems was studied. The ignition characteristics were determined and the specific aspects of the mechanisms were investigated. 


\section{Ignition by heated gas}

One of the ways of initiation of a SHS process is the ignition of metal in a hot gaseous oxidizer (ref.13-15). Specimens to be studied (10 $\mathrm{mm}$ in diameter) were embedded in asbestos cement insert flush with its lower face. This prevented contact of the side back surfaces of a specimen with the oxidizer and simultaneously decreased heat supply of the side surface due to conductive heat transfer and radiation. A gas medium of certain temperature and pressure was created in a pressure-tight chamber heated by $\mathrm{Ni}-\mathrm{Cr}$ alloy coil. The chamber had openings for visual observation of sample surface, for a spring sample injection device, and for gas inlet and outlet. Temperature in the volume was measured with the of chromel-copel thermocouple mounted in the chamber to be in close vicinity of a sample which temperature was measured with a differential chromel - copel thermocouple. A design of the chamber made it possible to get temperatures up to $600^{\circ} \mathrm{C}$ and pressures up to 75 atm. The injection device consisted of a body, a piston, and a piston rod. A pressure of air coming from a cylinder through an opening in the sample injection device displaces the piston and the rod rigidly mounted to the piston breaks a copper membrane isolating the sample from a hot gas and pushes the sample into the chamber. In order to prevent heating of samples, a cooler was installed in front of the chamber on the body of sample injection device. The operation takes about 0.2 $s$ which is considerably less than the time of process under study. Hydrodynamic perturbations in the chamber produced by sample introduction are insignificant as long as the piston rod to chamber cross section ratio is nearly $0.5 \%$. An ignition delay time was determined by emergence of intensive emission on the sample surface or by temperature break-down measured with a thermocouple mounted on the sample surface. Ignition of zirconium, titanium, and hafnium in oxygen was studied. The critical ignition temperature and delay time as functions of parameters of SHS systems and pressure were determined.

\section{Spark ignition}

Initiation by a high voltage discharge was first proposed as a method of determination of minimum ignition energy for gas suspensions and aerogels (refs.16 and 17). When studying the ignition of gas suspensions of metal powders, experiments are carried out in a pressure-tight explosion chamber. A powder is dusted with a vibrosieve batcher mounted over the starting electrodes. A spark is formed on discharging of a capacitor with a given energy. The same device is used for determination of minimum energy of dispersed solid powders. A special ignition unit consisting of an earthed metal cup with a dielectric insulator insert is utilized for the purpose. The cup is filled with a thin layer of substance to be studied. A spark strikes between an electrode and a special ring protrusion of the cup. Between successive sparks the cup turns by a prescribed angle thus providing the action on fresh portions of the substrate. An optimum thickness of product layer providing the highest probability of ignition for unchanged discharge curcuit parameters is determined. The spark ignition begins to come into practice of initiation of SHS processes now.

\section{Chemical (hypergolic) ignition}

A system to be ignited is instantaneously brought into contact with a reactive gaseous or liquid agent which results in evolution of large amount of heat at the contact surface sufficient for initiation of main reactions in the combustion process. It is definitely impossible to find a universal hypergolic igniter, this being a principal disadvantage of the method. On the other hand, its plain advantages are a comparatively simple design of ignition device, its reliability and possibility of using in a multiple recurrence mode. P.A.Rhein (ref.18) suggested to use gaseous or liquid $\mathrm{ClF}_{3}$ and $\mathrm{ClF}_{5}$ for ignition of metal ( $\mathrm{Al}, \mathrm{Mg}, \mathrm{Li}$, Ca, etc.)powders. I.T.Bryan and N.I.Sippel (ref.19) extended the range of systems ignited by these agents to $\mathrm{B}, \mathrm{B}_{4} \mathrm{C}, \mathrm{Zn}, \mathrm{Fe}, \mathrm{C}, \mathrm{W}, \mathrm{Mo}, \mathrm{Zr}$, etc. A synergistic hypergolic effect was discovered by Jain et al (ref.20). They observed the hypergolic ignition of mixtures of different solid amines with magnesium powder reacting with fuming red nitric acid. It is interesting to note that neither amines no magnesium have exhibited the hypergolic effect if taken separately. The ignition delay depending on component ratio in the mixture was determined in this work. The hypergolic ignition becomes in recent years to be used in technological practice for initiation of SHS reactions.

\section{Chemical oven}

It is widely practised to use systems with high heat content for initiation or change in mode of realization of SHS reactions (see,e.g. refs.21-27). Such a technique was called "chemical oven". It was employed in production of carbonitrides (ref.22). To maintain necessary conditions of the process a niobium to carbon ratio in the initial $\mathrm{Nb}-\mathrm{C}-\mathrm{N}$ ternary system was varied. Having one the highest possible combustion temperatures, the $\mathrm{Ti}+2 \mathrm{~B}+\mathrm{N}$ mixture played a part of chemical oven in the synthesis of tantalum nitrides (ref.23) while ${ }^{2}$ the $\mathrm{Ti}+$ $C$ system did the same in the synthesis of tantalum carbides (ref.24). In manufacturing of composite materials with a molibdenum-rhenium binder ( $\mathrm{ref} .25$ ) the $\mathrm{Ti}+0.7 \mathrm{C}$ mixture was used 
as a "fuel" for chemical oven. The high-temperature mixture of $\mathrm{Ti}+0.6 \mathrm{Si}$ was used for chemical oven in the production of low-temperature silicide $\mathrm{Mo}_{3} \mathrm{Si}$ (ref.26). To prepare $\mathrm{B}_{4} \mathrm{C}$ Z.A.Munir (ref.27) initiated a mixture of boron and carbon by high temperature boron + titanium mixture (the adiabatic temperature of $\mathrm{TiB}_{4}$ is $3190 \mathrm{~K}$ ).

\section{Electrothermal explosion}

A.S.Steinberg et al. (ref.28 and 29) proposed electrothermal explosion technique for use in initiation of SHS processes. The specific feature of ETE is heating a sample up to its ignition not by means of external heat transfer but due to passing of electric current through the specimen. The heating is carried out with the use of a powerful step-down transformer which permits an amperage of up to $10^{4} \mathrm{~A}$ to be passed. A power supply level of Joule heating is controlled with a thyristor power regulator. The power is measured with a mirror-galvanometer oscillograph. A surface temperature is determined by luminance of surface glow. For this purpose, an image of specimen is formed with a lens on an entrance diaphragm of photodiode, a signal from the latter being transferred (after its amplification) to the oscillograph also. Calibration of temperature measurement system is carried out with the use of standard tungsten lamp. This procedure was used in a study on high temperature interaction of titanium and tantalum with carbon.

\section{Ignition using microwave energy}

R.C.Dalton et al (ref.30) managed to initiate a SHS process by heating with microwave field. $700 \mathrm{~W}$ and $6.4 \mathrm{~kW}$ microwave ovens with a frequency of $2.45 \mathrm{GHz}$ were used. The following mixtures were studied in the experiments: $\mathrm{Ti}+\mathrm{C}, \mathrm{Si}+\mathrm{C}, 4 \mathrm{~B}+\mathrm{C}, \mathrm{Ti}+2 \mathrm{~B}, \mathrm{Mo}+2 \mathrm{SI}$, $5 \mathrm{Ti}+$ $3 \mathrm{Si}, 2 \mathrm{Al}+\mathrm{N}_{2}, 2 \mathrm{Ti}+\mathrm{N}_{2}$, and $3 \mathrm{TiO}_{2}+4 \mathrm{Al}+3 \mathrm{C}$. Specimens of 0.5 and 1.1 in in diameter were used. The specimens were compacted to their initial porosity of 17-50\%. The samples were placed into a fused silica crucible which then was surrounded by microwave-trasparent alumina-silicate refractories. The combustion of samples (except for metal-gas systems) was carried out under argon atmosphere. In order to provide necessary purity and to saturate the surrounding in the case of metal-nitrogen reaction,purging with the gas started 5 minutes earlier than microwave supply was turned on. The completeness of reaction was checked with $\mathrm{X}$-ray phase analysis.

\section{Thermal explosion on linear heating}

One of the types of initiation of SHS-process (refs.31-34) is heating a sample at a constant rate ended with thermal explosion. The rate of heating might be constant ( $70 \mathrm{~K} \mathrm{~min}^{-1}$, ref.31) or varying (from 0.5 to $5 \mathrm{~K} \mathrm{~min}^{-1}$, ref.32). Cylindrical samples of 1.5 to $3 \mathrm{~cm}$ in diameter with different starting porosity (from 20 to $80 \%$ ) were pressed from the powder under investigation. A special hole for thermocouple was drilled out in a sample. The specimens were placed into a constant pressure bomb which was filled then with an inert gas under a pressure of 1.5 to 2 atm. The $\mathrm{Al}+\mathrm{Ni}, 3 \mathrm{Cu}+\mathrm{Al}$, and $2 \mathrm{Cu}+\mathrm{Al}$ intermetallide systems (ref. 31-33) and $\mathrm{TiB}_{2}+\mathrm{Ni}$ system (ref. 34) were initiated. Comparison of products obtained in the combustion mode and in the thermal explosion mode by their phase and chemical composition has shown (ref.31) that the both modes are equally applicable in the synthesis of intermetallide compounds and intermetallide base alloys or ligatures. It is emphasized that difference between combustion and thermal explosion may lead to essentially different in the synthesis of compounds with gas or liquid filtration in a porous system.

\section{MATHEMATICAL DESCRIPTION OF IGNITION PROCESSES}

Usually exercised in mathematical description of ignition of such complicated in a physico-chemical respect mixtures as SHS systems are approaches developed in the thermal theory of ignition generalized in a review by A.G.Merzhanov and A.E.Averson (ref.35) and in a monograph by V.N.Vilyunov (ref.36). The simplest mathematical model of ignition, in which an ignited compound is represented as a semiinfinite uniform space with a flat surface where the reaction takes place, is given to be described with a system of equation:

$$
\begin{aligned}
c \rho \frac{\partial T}{\partial t} & =\lambda \frac{\partial^{2} \mathrm{~T}}{\partial \mathrm{x}^{2}}+Q \mathrm{k}_{0} \exp (-\mathrm{E} / \mathrm{RT})(1-\eta)^{\mathrm{n}} \\
\frac{\partial \eta}{\partial \mathrm{t}} & =\mathrm{k}_{\mathrm{o}} \exp (-\mathrm{E} / \mathrm{RT})(1-\eta)^{\mathrm{n}}
\end{aligned}
$$

with the initial condition of $t=0, T=T_{1}$, and $\eta=0$, where $T$ is the temperature, $x$ the coordinate, $t$ the time, $c$ the heat capacity, $\rho$ the density, $\lambda$ the heat conductivity, and $\phi$ the bulk rate of heat evolution given as $\phi=Q k_{0} \exp (-E / R),(1-\eta)^{n}$, in the case of $n-t h$ order reaction, $Q$ the heat of reaction, $k_{0}$ the pre-exponential factor, $\eta$ the degree of conversion, $\mathrm{n}$ the reaction rate order, $\mathrm{E}$ the activation energy, and $\mathrm{R}$ the universal gas constant. 
Conditions on the surface can be quite different depending on mechanism of heating. They are defined by boundary conditions, the simplest of the latter being $T_{s}=$ const (the constancy of surface temperature) and $q_{s}=$ const (the constancy of heat flow supply to the surface). As far as condensed systems are concerned, the equation for a heat evolution rate makes sense only in the case when all of the components of mixture melt and have time to be mixed in the warm-up zone thus making the reactions to occur homogeneously. In the more common case when at least one of the initial components does not melt, the reaction takes place due to transport of the components through a layer of product formed. An equation for a bulk rate of heat evolution is proposed (ref.37) which takes into account diffusion slowing down of this layer, the layer production being assumed to occur in a way that solid particles of one reactant are immersed in a homogeneous medium of another reactant and the surface layers of reacting particle are replaced by the reaction product layer as the reaction proceeds and this latter layer separates the reacting components. A heterogeneous system is considered as a uniform medium in the thermal respect. The heterogeneity of system is implicitly taken into account via the kinetics of heat evolution prescribed. This assumption is close to real in the following three cases.

1. One of the components is liquid or gaseous in its initial state (in this case the filtration does not have to restrict the rate of interaction).

2. Both of the components are solid in their initial states but one of them melts in the warm-up zone.

3. Both of the components remain solid in the reaction zone but a particle size of one the reactants is considerably less than that of the other.

With the above assumptions, a function $\phi$ can be expressed as

$$
\phi=Q \rho(m+1)(1-\eta)^{m} \frac{k_{0} \exp (-\kappa \eta)}{R_{e}^{n+1} n} \exp (-E / R T)
$$

where $m$ is the index of particle shape, $R_{e}$ the effective radius of particle, and $n$ and $\kappa$ the kinetic parameters. Using a heat evolution function written in the form of eq.2, we got a numerical solution of a problem on ignition of heterogeneous systems with condensed phase products by constant heat flux (ref.38). Since the experiments (refs.6 and 7) involved high ignition temperatures, radiative heat losses were taken into account in solution of the problems in these boundary conditions.

To solve the problem on combustion wave ignition a conjugate system of heat conduction and reaction rate equations were written (ref.39) modeling a transition combustion process in two cylindrical samples of a radius $r$ brought into contact (assuming the temperature to be uniform along the diameter):

$$
\begin{aligned}
& c_{1} \rho_{1} \frac{\partial T}{\partial t}=\lambda_{1} \frac{\partial^{2} T}{\partial x^{2}}+Q_{1} k_{o l} \exp (-E / R T) \varphi(\eta)-\frac{2 \alpha}{r}\left(T-T_{0}\right)-\frac{2 \varepsilon}{r} \sigma_{0}\left(T^{4}-T_{0}^{4}\right) \\
& \frac{\partial \eta}{\partial t}=k_{01} \exp (-E / R T) \varphi(\eta)
\end{aligned}
$$

with boundary conditions:

$$
x=0 \begin{aligned}
& \lambda_{1} \frac{\partial T_{1}}{\partial x}=\lambda_{2} \frac{\partial T_{2}}{\partial x}, \quad x=+\infty, T=T_{1} \\
& T_{1}(0, t)=T_{2}(0, t), x=-\infty, T=T_{c}
\end{aligned}
$$

where $\alpha$ is the coefficient of heat transfer to the environment, $\varepsilon$ the emissive factor, $\varphi(\eta)=(1-\eta)^{n}, \sigma_{0}$ the Stefan-Boltzmann constant, $T_{0}$ the temperature of surroundings, $T_{c}$ the combustion temperature, and $\mathrm{i}=1,2$ the subscripts denoting priming ( $\mathrm{i}=1)$ and ignited ( $\mathrm{i}=2$ ) systems, respectively.

To elucidate the aspects related to slowing down of reaction by a product layer, with the presence of components of different dispersity and form, and with the thickness of original oxide film, a system of equations similar to set of eqs.3 was used (ref.40) where the bulk rate of heat evolution was written in the form of eq.2. One of the versions of theoretical description of heterogeneous systems is the analysis of "sandwich" type models where a real heterogeneous system is represented as a set of ordered layers of initial components (ref.8 and 41). 
Mathematical description of the process of ignition of condensed systems with filtration of gaseous reactant (refs.42-44) is of especial interest. Considered there is a set of heat and mass transfer equations in a gas and in a porous medium with nonlinear sources reflecting exothermic interaction of reactants. It is assumed that gas temperature and temperature of the porous framework are the same, the filtration obeys the Darcy's law, and change in porosity in the course of reaction may be neglected. Analysis of this system of equations allowed the authors to clarify a question on the effect of pressure and composition of oxidizing medium on ignition characteristics, to determine the critical ignition properties for pulsed energy supply, and counter-current gas filtration, and to obtain some other interesting results.

Both numerical (see, e.g. refs.37-43.45, and 46) and approximate analytic methods are extensively used in theoretical consideration of the process of ignition of SHS systems. A number of problems on initiation of SHS processes was solved with the use of "critical condition" technique (refs.47 and 48) in which the solution of heat conduction equation for a chemically inert body was utilized. The moment of ignition in this case is determined out of a specially stated critical condition including kinetic parameters and quantities describing a temperature field. The meaning of this condition is as follows. The ignition takes place at the moment when the rates of heat arrival from an external source and chemical reaction are equal. Some years ago B.S.Seplyarskii (ref.49) worked out an approximate theory of ignition based on the relation of ignition characteristics with the parameters of stationary combustion wave, a maximum temperature in the latter being equal to the combustion temperature. This theory was successfully applied in the analysis of modes of ignition by hot surface (ref.49), with gas filtration (ref.44), and with occurrence of two consecutive reactions with an endothermic stage (ref.50). Agreement of some data obtained in ref.49 with the numerical computations was analyzed (ref.51).

\section{MOST IMPORTANT RESULTS}

\section{Basic characteristics of ignition}

One of the important features of SHS systems is their high ignition energy.Comparison of experimental data (refs.6 and 7) by dependence of the ignition energy on heat flux density for different SHS systems initiated by readiant flux with similar data for systems with gaseous products (mixed and ballistite gun powders, explosives, and cellulose base materials) has shown that the ignition energies of SHS systems are by 1-2 order of magnitude higher than these of the other systems. Very high ignition energies were obtained also for laser induced ignition (ref.8) Moreover, there is a specific property of these system consisting in unusually strong dependence of ignition delay time on heat flux density, especially in the case of systems with carbon. A significant effect is exerted on ignition characteristics (refs.6-8)by size (Fig.3), shape, and structure of particles and by sample density (Fig.4). The strong influence of porosity on ignition characteristics was pointed out by V.I.Rozenband et al. (ref, 13).

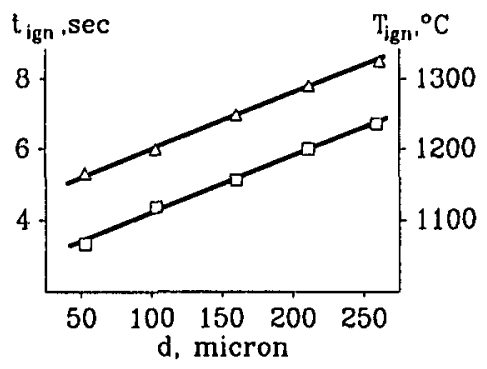

Fig.3. Ti - particle size dependence of ignition delay time and ignition temperature. Sys tem: $T i+C ; q=9.6 \cdot 10^{5} w / m^{2}$

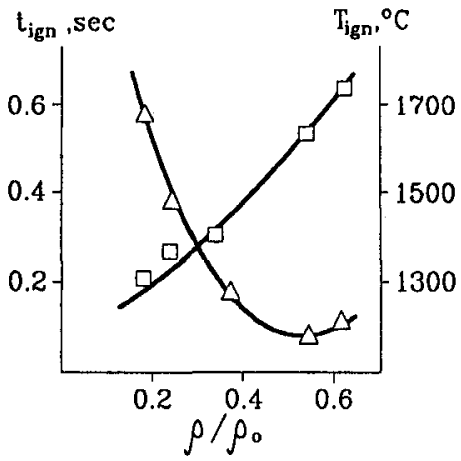

Fig.4. Relative density dependence of ignition delay $t$ ime and ign $i t i$ on temperature. System: $T \mathbf{i}+\mathrm{C}$,

$\mathrm{Ti}-$ particl e size $<100 \mu \mathrm{m}$, $q=1.84 \cdot 10^{6} \mathrm{w} / \mathrm{m}^{2}$

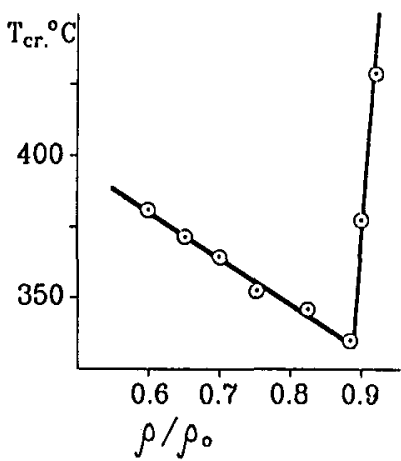

Fig.5. Relative density dependence of critical ignition temperature. System : $\mathrm{Zr}+\mathrm{O}_{2}$, sample diameter $10 \mathrm{~cm}, \mathrm{Zr}$ - particle size $<45 \mu \mathrm{m}$, oxygen pressure - 1 atm. 
They observed a dramatic increase in critical temperature of ignition of zirconium in oxygen beginning from a certain relative density of a sample (Fig.5). Increasing sample density affects the process of inflammation in an equivocal way resulting, on one hand, in increasing overall reaction surface per unit volume and, on the other hand, decreasing the amount of oxidizer located in pores and retarding its supply from the bulk because of poorer gas permeability of more dense samples. Estimations show that the latter factor predominate at larger relative densities which leads to a significant increase in ignition delay time. U.I.Goldschleger et al. (ref.52) studied the effect of thickness of original oxide film on ignition of zirconium. Special pretreatment of samples (they were kept in argon flow at a temperature of $500^{\circ} \mathrm{C}$ for some period) was carried out. The original oxide film was found to affect the kinetics of oxidation and, correspondingly, the ignition process essentially. Approximate analytic equations allowing the basic characteristics of ignition (delay time, temperature and energy of ignition) to be calculated depending on kinetic, thermophysical, etc. parameters determining the development of the processes were derived (refs.38, 53-55).

\section{Aspects of attaining stationary combustion mode}

The physical picture of transition process occurring on initiation of SHS systems was studied both theoretically (refs.39,40 and 45) and experimentally (refs.3-5). On hot surface initiation (ref.45) the whole of the transition process ( $t_{f}$ ) can be splitted into two stages, viz. formation of nonstationary front $\left(t_{1}\right)$ and the process of establishing of combustion ( $t_{2}$ ) ending by outcome to the stationary combustion conditions $\left(t_{f}=t_{1}+t_{2}\right)$. Depending on a value of $Z=c\left(T_{-}-T_{1}\right) / Q$ there is either induction ignition mode $(Z<0.7)$ or "burning" mode $(Z>1.7)$ attained. In the conditions of induction mode, a mixture neighbouring to the hot surface is warmed up and partially reacts and a nonstationary combustion front is formed then. Establishment of combustion process is over when the preliminarily warmed up mass of the mixture is completely burnt. The nonstationary combustion rate first increases and then, attaining its maximum value, decreases because of decreasing temperature of the mixture in front of the combustion wave. Under conditions of burning mode the combustion front is formed almost instantaneously and the further nonstationarity of the process is due to occurrence of heat flow to the combustion zone. The non-stationary combustion rate decreases monotonically down to the value of stationary rate.

For the combustion wave ignition as well as for the hot surface ignition, the induction mode and the "burning" mode can be distinguished. This splitting is carried out first of all in accordance with characteristic times ratio of the transition process. If the time of combustion wave formation in an ignited system is noticeably larger than the time of front establishing then the induction ignition mode is realized while if the time ratio is opposite, the "burning" mode is observed. The stationary combustion is settled after one or several oscillations of combustion rate around its stationary value. Development of the transition process is determined by ratio of heat reserves in the combustion front of priming and ignited systems necessary for their stationary combustion and by ratio of relevant heat flux densities.

\section{Stability of transition processes}

Stability of combustion wave transition from one reacting system to another was considered in a series of studies by A.G.Strunina and by the author himself with the co-workers (refs.3,4,55-59). As has been already mentioned, the transition over the interface of contacting gasless systems involves two non-stationary processes, viz. the combustion front formation in an ignited system and establishing of stationary combustion conditions. The break-down of stable transition (decay of combustion wave) can occur in each of these processes. A limit by ignition is realized in the first case and the limit by combustion in the second case. If an ignited system is under conditions when its combustion must occur in one of unstable (but ordered or established) modes, e.g. in pulsating or spinning mode, it is impossible to find an igniter which could provide a stable stationary combustion mode. In the course of initiation, pulsations emerging because of difference in parameters of igniter and ignited system are applied on the complex unstable process. Comparison of results obtained with different procedures of initiation of systems burning in the region of unstable stationary mode has shown that the nonmonotonic change in frequency of (vibrational or rotational) motion of the front can be considered as the sum of natural frequency inherent to unstable burning system and the frequency of damped oscillations caused by perturbation of the process upon transition over the interface boundary. An increase in duration of depressions between separate flashes in case of heat losses to the surroundings can result in extinction of the ignited system. 
$t_{d}, \sec$

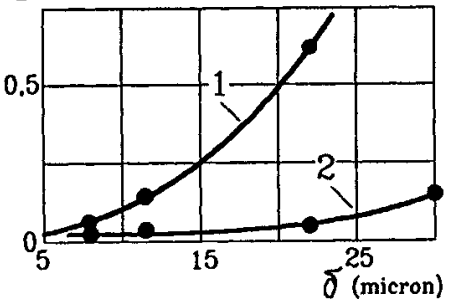

Fig.6. Efrect of dispersity on time of depression between pulsation in an ignited system. 1 - Termite systems, $2-\mathrm{Al}+\mathrm{Co}$.
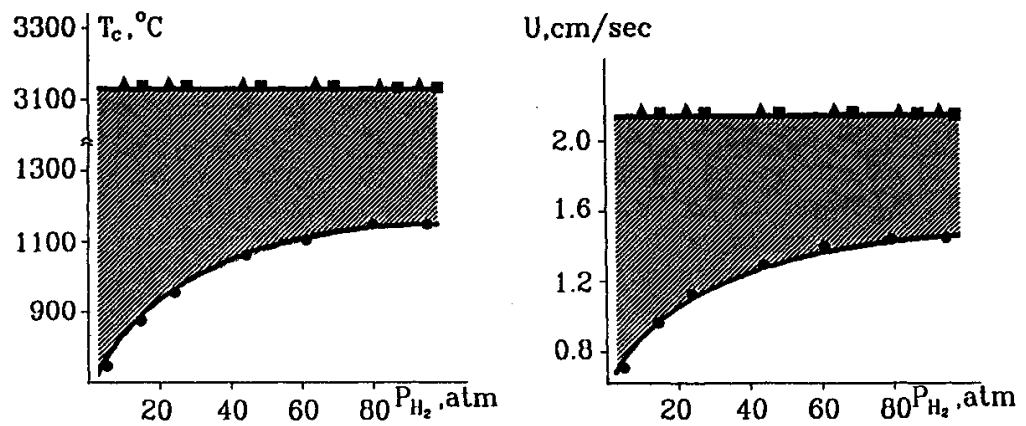

Fig.7. $\mathrm{P}_{\mathrm{H}_{2}}$ - dependence of combust $\mathrm{i}$ on temperature and combustion rate. System: $\mathrm{Zr}+\mathrm{C}$;

- ignition from $\mathrm{Ti}+2 \mathrm{~B}\left(3000^{\circ} \mathrm{C}\right)$;

A - ignition from $\mathrm{Mo}+2 \mathrm{Si}\left(1700^{\circ} \mathrm{C}\right)$;

- ignition from $\mathrm{Ti}+\mathrm{H}_{2}\left(1000^{\circ} \mathrm{C}\right)$.

This was observed, e.g. with the Al + Co system (ref.5). A noticeable effect of dispersity on time of depression between pulsations in an ignited system was observed (Fig.6). The critical conditions of transition of combustion wave can be realized in the case of

1. a limited heat reserve in an igniter (a low heat of reaction or a small weight of igniter sample),

2. large difference in activation of combustion of igniter and ignited system,

3. strong heat withdrawal from an igniter to the ignited mixture (a large heat conductance of ignited system) and the other way around (a large heat conductance of slag of burnt igniter), and

4. large heat losses to the surroundings.

An excess enthalpy $\Delta H$ and a rate of excess enthalpy change with respect to combustion time of warmed up layer $\Delta H / t$ determining initiation conditions are to a certain extent complex characteristics of the process as depending on a heat content of the mixture, thermophysical properties, activation of the process, and heat losses (which determine a combustion rate together with the other parameters). Analysis shows that the cause of combustion extinction is different for different types of initiation modes. The transition of combustion wave from one reacting system to another in the induction mode becomes impossible due to the fact that the rate of heat removal from the formed combustion front of ignited system $\Delta H_{2} / t^{\prime \prime}$ becomes much more then that of from the igniter $\Delta \mathrm{H}_{1} / \mathrm{t}^{\prime}$. In the burning mode, the cause of decay of the process is determined by ratio of heat reserves in the combustion front of igniter and ignited system $\left(\Delta \mathrm{H}_{1}\right.$ vs. $\left.\Delta \mathrm{H}_{2}\right)$. A stable transition of combustion wave from one reacting system to another becomes impossible if the excess enthalpy of igniter is considerably larger than the excess enthalpy of ignited system. Numerical and approximate analytic calculations of the region of stable transition modes were carried out and the calculated data were compared with experimental results obtained with termite systems (ref.56).

\section{Non-uniqueness of stationary combustion mode}

Studying stepwise combustion theoretically, B.I.Khaikin and S.I.Khudiaev discovered (taking two competing parallel reactions as an example) two stable stationary modes (ref.60). If the activation energies for two reactions differ considerably from each other then only one of the reactions occurs at low temperatures while only the other does at high temperatures. If under these conditions the low-temperature reaction has a small heat of reaction but the high-temperature reaction has a large one then it is possible to realize the combustion process at different temperatures and rates. A pathway of reaction will depend on conditions of ignition. This very interesting conclusion was proved experimentally by N.A.Martirosyan, S.K.Dolukhanyan, and A.G.Merzhanov (ref.61). It turned out that combustion of zirconium and carbon black powders in hydrogen with the low-temperature ignition occurred in a low-temperature mode with production of zirconium hydrides. When mixtures with high combustion temperatures were taken as ignition sources, the high-temperature mode with zirconium carbonitride formation was realized. In the case of titanium-hydrogen system, the interaction of titanium and hydrogen took place with the low-temperature ignition and the reaction of titanium with carbon did with the high-temperature ignition (Fig.7).

It was also found that ignition conditions affect not only stationary mode of combustion wave but the critical conditions of mode change (Fig.8). E.A.Nekrasov at al. recently observed (ref.62) the non-uniqueness of combustion mode for Ti-B-Fe system. 

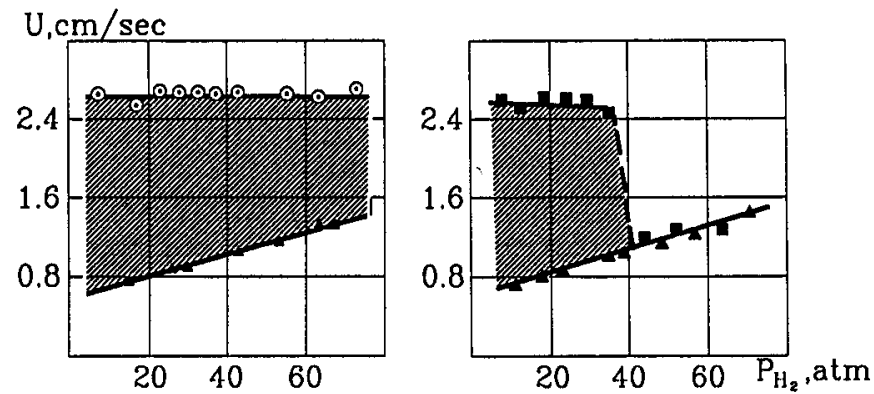

Fig.8.

$\mathrm{P}_{\mathrm{H}_{2}}$-dependence of combustion rate.

System: $\mathrm{Ti}+0.7 \mathrm{C}$;

- - ignition from $\mathrm{Ti}+\mathrm{C}(3200 \mathrm{~K})$;

- ignition from Mo+2Si (1900K);

$\Delta$ - ignition from $\mathrm{Ti}+\mathrm{H}_{2}(1200 \mathrm{~K})$.

The issue of non-uniqueness of stationary mode was extensively studied theoretically. The non-uniqueness on occurrence of consecutive reactions with an endothermic stage was considered (ref.63). The non-uniqueness having thermal origin was exhibited with the use of "sandwich" type model (refs.62 and 64). The problem of non-uniqueness was studied with a regard for such factors as instability of stationary combustion front, two-dimensionality, possibility of degenerating of low-temperature mode because of strong dilution, etc (ref.65). Consideration of nonstationary combustion modes of gas suspensions showed (ref.66) that the non-uniqueness can be connected with the existence of competing mechanism of heat transfer. In all of the above cases, the initiation conditions determined which of the possible combustion modes would be realized.

\section{Choice of optimum conditions of ignition}

Available theoretical and experimental data (refs.3-5. 38-40, and 53-56) make it possible to carry out approximate calculations of ignition characteristics for initiation of SHS process as well as to give recommendations on a choice of optimum conditions for ignition. In some cases it is necessary to reduce the ignition delay time. It has been shown (ref.67) that igniters with a small excess enthalpy should be used for the purpose, the temperature conduction coefficient of igniter being desirably larger than that of an ignited system (the igniter in this case is burnt at combustion rate and combustion temperature larger than the stationary values at the interface boundary with the ignited system). It turned out that the less the ignition energy with respect to excess enthalpy of ignited system, the better organized the ignition process since not only energy consumption was low but the ignition time decreased under these conditions. Various ways of expansion of ignition limits were suggested (ref.67). Even with fixed compositions of reacting systems the ignition region can be extended by reduction of heat losses to the environment, by decrease in density of compaction of ignited system, and by increase in density of compaction of igniter. Application of separating layers on the interface boundary between the systems also facilitates the expansion of ignition region. The separators can have the heat conductivity both smaller (like ashless filtres) and larger (metal foil) than that of the igniter. Separators with poor heat conductivity lead to raising thermal wave of ignition upon approaching to the ignited system and to initiating the reaction by more powerful heat flow. A metal foil having low melting point can improve the thermal contact of igniter with ignited system on fusion.

\section{REFERENCES}

1. A.G.Merzhanov, V.M.Shkiro and I.P.Borovinskaya, Certif.N 255221,1967, Appl.N 1170735; France Pat.N 2088668, 1972; US Pat.N 3726643,1973, U.K.Pat.N 1321084.

2. A.G.Merzhanov and I.P.Borovinskaya, Dokl.Akad.Nauk SSSR 204, 366-369 (1972).

3. V.I.Yermakov, A.G.Strunina and V.V.Barzykin, Fiz. Gor. Vzryva 2, 211-217 (1976); $\underline{6}, 36-44$ (1978).

4. S.V.Kostin and A.G.Strunina, Fiz.Gor. Vzryva 5, 19-24 (1979).

5. S.V.Kostin, A.G.Strunina and V.V.Barzykin Fiz.Gor.Vzryva $\underline{5}, 32-38$ (1982); 2, 32-38 (1988).

6. V.P.Stovbun, T.I.Kedrova and V.V.Barzykin, Fiz.Gor.Vzryva 3, 349-354 (1972).

7. V.V.Barzykin and V.P.Stovbun, Combust.Processes in Chem.Technology and Metallurgy (Russ), 274-283, Chernogolovka (1975).

8. P.V.Phung and A.P. Hardt, Combust.Flame 14, 375-380 (1970).

9. L.M.Vidavskii, G.V.Khil'chenko, I.I.Korotkevich, G.P.Polunina and V.I.Spitsyn, Dokl. Akad. Nauk SSSR 219, 1157-1160 (1974).

10. 1.I.Korotkevich, G.V.Khil'chenko, G.P.Polunina and L.M.Vidavskii, Fiz.Gor.Vzryva $\underline{5}, 61-67$ (1981).

11. P.Dimitriou, V.Hlavacek, S.M.Valone, P.G.Behrens, G.P.Hansen and J.L.Margrave, AICHE Journal 35, 1085-1096 (1989).

12. J.L.Deming, J.H.Weber and L.C.Tao, Combust.Flame 14, 375-380 (1970).

13. V.I.Rozenband, V.A.Chichev and L.F.Afanasieva, Fiz. Gor. Vzryva 1 31-36 (1976).

14. E.V.Chernenko, V.I.Rozenband and V.V.Barzykin, Fiz.Gor.Vzryva 1, 66-69 (1979). 
15. U.I.Goldshleger, E.A.Makarova and V.I.Rozenband, Fiz.Gor.Vzryva 2, 305-310 (1977).

16. V.T.Monachov, Research Methods of Fire Hazard of Materials,(Russ), 286-289, Chimiya, Moskva (1979).

17. A.B.Ryzhik, Fiz.Gor.Vzryva 6 , 53-57 (1978).

18. P.A.Rhein, Jour.of Spacecraft and Rockets $6,1328-1329$ (1969).

19. I.T.Bryan and N.I.Sippel, Journ.of Spacecraft and Rockets 8, 2-5 (1971).

20. S.R.Jain, R.Rao and K.N.Murthy, Combust.Flame 71, 233-243 (1988).

21. A.G.Merzhanov, 1.P.Borovinskaya, V.Maslov, at al, Certif.N 460115,1974, Appl.N 1960130,1973; "Invest.Bull." 6 , (1975).

22. A.B.Avakyan, A.R.Bagramyan, I.P.Borovinskaya, S.L.Grigoryan and A.G.Merzhanov, Combust.Processes in Chem. Technol. and Metallurgy, (Russ), 98-113, Chernogolovka (1975).

23. I.P.Borovinskaya, A.G.Merzhanov, A.N.Pitylin and V.Sh.Shekhtman, Combust.Processes in Chem. Technol. and Metallurgy, 113-118, Chernogolovka,(1975).

24. V.M.Shkiro, G.A.Nersisyan, I.P.Borovinskaya, A.G.Merzhanov and V.Sh.Shekhtman, Powder Metallurgy 4, 14-17 (1979).

25. I.P.Borovinskaya, G.A.Vishnyakova, V.M.Maslov and A.G.Merzhanov, Combust.Processes in Chem. Technol. and Metallurgy, 141-149, Chernogolovka (1975).

26. A.R.Sarkisyan, S.K.Dolukhanyan, I.P.Borovinskaya and A.G.Merzhanov, Fiz.Gor.Vzryva 3 , 49-55 (1978).

27. Z.A.Munir, Ceram.Bull. 67, 342-349 (1988).

28. V.A.Knyasik, A.G.Merzhanov, V.B.Solomonov and A.S.Shteinberg, Fiz.Gor.Vzryva $3,69-73$ (1985).

29. V.A.Knyasik, A.G.Merzhanov and A.S.Shteinberg, Dokl.Akad.Nauk SSSR 301, 899-902 (1985).

30. R.C.Dalton, I.Ahmand and D.E.Clark, Ceram.Eng.Sci.Proc. 11(9-10), 1729-1742 (1990).

31. V.I.Itin, A.D.Bratchikov and L.N.Postnikova, Powder Metallurgy $5,24-28$ (1980).

32. K.A.Philpot, Z.A.Munir and J.B.Holt, J. Mater. Sci.22, 159-169 (1987).

33. L.L.Wang, Z.A.Munir and J.B.Holt, Metal Trans.B 21B, 567-577 (1990).

34. Y.Miyamoto, Seramikkussu (J.Japan Cer.Soc.) 22, 489-495 (1987).

35. A.G.Merzhanov and A.E.Averson, Combust. Flame 16, 89-124 (1971).

36. V.N.Vilunov, Ignition Theory of Condensed Substance (Russ.), p.189, Nauka, Novosibirsk (1984).

37. A.P.Aldushin, T.M.Martemjanova, A.G.Merzhanov, B.I.Khaikin and K.G.Shkadinsky, Fiz. Gor. Vzryva 2, 202-212 (1972).

38. V.P.Stovbun, V.V.Barzykin and K.G.Shkadinsky, Fiz. Gor. Vzryva 2, 147-155; $\underline{6}, 821-827$ (1977).

39. A.G.Strunina, T.M.Martemjanova, V.V.Barzykin and V.I.Ermakov, Fiz. Gor. Vzryva 4, $518-525$ (1974).

40. A.G.Strunina, A.N.Firsov and S.V.Kostin, Fiz. Gor. Vzryva 5, 24-30 (1981).

41. B.I.Khaikin, Combustion and Explosion. (Proc. 4th Alli-Union Symp. on Comb. Expl.), p.p.121-137, Nauka, Moskva (1977).

42. E.V.Chernenko, T.A.Ivleva, V.I.Rosenband and V.V.Barzykin, Fiz. Gor. Vzryva $\underline{1}, 15-22$ (1980).

43. A.Yu.Snegirev and V.A.Talalov, Combust. of Condensed Systems (Proc. 9th All-Union Symp. on Comb. Expl.). p.p.61-64, Chernogolovka (1989).

44. B.S.Seplyarsky, Fiz. Gor. Vzryva 1, 3-12 (1991).

45. K.G.Shkadinsky, Fiz. Gor. Vzryva 3 , 332-336 (1971).

46. B.L.Kopeliovich and A.K.Nesterov, Fiz. Gor. Vzryva 5, 5-8 (1987).

47. A.E.Averson, V.V.Barzykin and A.G.Merzhanov, Dokl. Akad. Nauk SSSR 178, $131-134$ (1968).

48. J.W.Enig, Proc. Roy. Soc. A. 305, 205-217 (1968).

49. B.S.Seplyarsky, Combust. of Condensed Systems (Proc. 8th All-Union Symp. on Comb. Expl.), p.p. 98-101, Chernogolovka (1986).

50. K.Yu.Voronin and B.S.Seplyarsky, Combust. of Condensed Systems (Proc.9th All-Union Symp. on Comb. Expl.), p.p. 64-67, Chernogolovka (1989).

51. I.G.Dik and A.M.Selikhovkin, Fiz. Gor. Vzryva 4, 9-11 (1989).

52. U.I.Goldschleger, E.A.Makarova and V.I.Rozenband, Fiz. Gor. Vzryva 2, 305-310 (1977).

53. S.V.Kostin, A.G.Strunina and V.V.Barzykin, Fiz. Gor. Vzryva 1 , 93-98 (1986).

54. A.G.Strunina, A.V.Dvoryankin, S.V.Kostin and V.V.Barzykin, Combustion of Compound Charges of Non-gasifying Systems and Computation of the Major Characteristics for Transitional Processes, Preprint DICh.Ph USSR Acad. Sci., Chernogolovka (1988).

55. A.G.Strunina, N.I.Vaganova and V.V.Barzykin, Fiz. Gor Vzryva 6 , 835-845 (1977).

56. A.G.Strunina and V.V.Barzykin, Archivum Combustions $5,191-203$, (1985).

57. A.G.Strunina, V.I.Yermakov and Barzykin, Fiz. Gor. Vzryva 4, 42-50 (1978)

58. A.G.Strunina, V.l.Yermakov and E.A.Averson, Fiz. Gor. Vzryva 4. 77-84 (1979).

59. A.G.Strunina, V.1.Yermakov, S.V,Kostin and V.V.Barzykin, Fiz. Gor. Vzryva 4. 3-8 (1989).

60. B.I.Khaikin and S.I.Khudiaev, Dokl. Akad. Nauk SSSR 245, 155-158 (1979).

61. N.A.Martirosyan, S.K.Dolukhanyan and A.G.Merzhanov, Fiz. Gor. Vzryva 5, 39-42; $6,22-24$ (1983).

62. E.A.Nekrasov, A.M.Timokhin and A.T.Pak, Fiz. Gor. Vzryva 5, 79-85 (1990).

63. E.A.Nekrasov and A.M.Timokhin, Fiz. Gor. Vzryva $5,17-22 ; 4,21-28$ (1984).

64. T.P.Ivleva, A.G.Merzhanov and K.G.Shkadinsky, Dokl. Akad. Nauk SSSR 256, 897-900 (1981).

65. T.P.Ivleva, P.M.Krishenik, A.G.Merzhanov and K.G.Shkadinsky, Chem. Phys., (Russ.) 9 1259-1264 (1983).

66. P.M Krishenik and K.G.Shkadinsky, Chem. Phys. (Russ.) 11,1566-1571 (1988).

67. A.G.Strunina, V.1.Yermakov, S.V.Kostin and V.V.Barzykin, Fiz. Gor. Vzryva 4, 3-9 (1981). 